\title{
Analysis of the variations of measured values in continuous long-term geodetic monitoring
}

\author{
Jan Vaněček \\ Department of Special geodesy, Faculty of the Civil Engineering \\ Czech Technical University in Prague \\ Thákurova 7, 16629 Prague 6, Czech Republic \\ jan.vanecek.2@fsv.cvut.cz
}

\begin{abstract}
A geodetic measurement of shifts and deformations by total station is a well-known and widely used method. There is presented the analysis of the variations over time of the measured values in continuous geodetic monitoring in this paper. There are used measured data from a specific monitoring system of a surface mine in the time period from January 2006 to July 2010 in the analysis.

The aim of the analysis is to describe linear trend and periodic changes in measured data (horizontal direction, zenith angle and slope distance). The main method of the analysis is a linear-harmonic function approximation.
\end{abstract}

Keywords: Measurement of shifts, least squares adjustments, linear and harmonic approximation, total station, continuous monitoring.

\section{Introduction}

Special branch of engineering geodesy is a measurement of shifts and deformations, which includes a special case - continuous monitoring. Measuring of the shift is regulated in standards, e.g.in The Czech republic CSN 730405, and also described in academic textbooks (e.g. [10]).

This branch of geodesy is dedicated to measure the objects periodically over time and includes many applications, e.g. monitoring of bridges (e.g. [5]), tunnels (e.g. [3]) or historical buildings [8]) and vertical ground deformation measuring (e.g. [1]) or even sub-millimetre level measuring of structures (e.g. [2]). The measurements are usually realized by the terrestrial methods (e.g. [9]), by the global navigation satellite systems methods or sometimes is advantageously used complex monitoring systems consist of geodetic and geotechnical instruments [6]).

A special case is the continuous monitoring, where the measuring machine records the measured values 24 hours a day, 7 days a week and 365 days in the year. This procedure is used for monitoring of the specific structures or other objects, which creates a large risk of damage to lives and property. An example might be the monitoring of the slopes, which are vulnerable to landslide (e.g. [4]). There is useful to know in the processing and evaluation of the obtained results, whether the measured value does not change in time in some way other than by the shifts of the target points. It means that the measured values in time grow linearly, drop linearly or their values periodically change.

Geoinformatics FCE CTU 15(1), 2016, doi:10.14311/gi.15.1.2 
The aim of this article is to describe the analysis of the measured values of the total station, which is used for monitoring of the stability of the Krušne mountains ${ }^{1}$ slopes.

\section{Description of the monitoring system}

The data used for the analysis of the development of the measurements was obtained from Severní energetická a. s. This company owns the surface mine ČSA, where is installed a monitoring system observing landslides in the Krušné mountains.

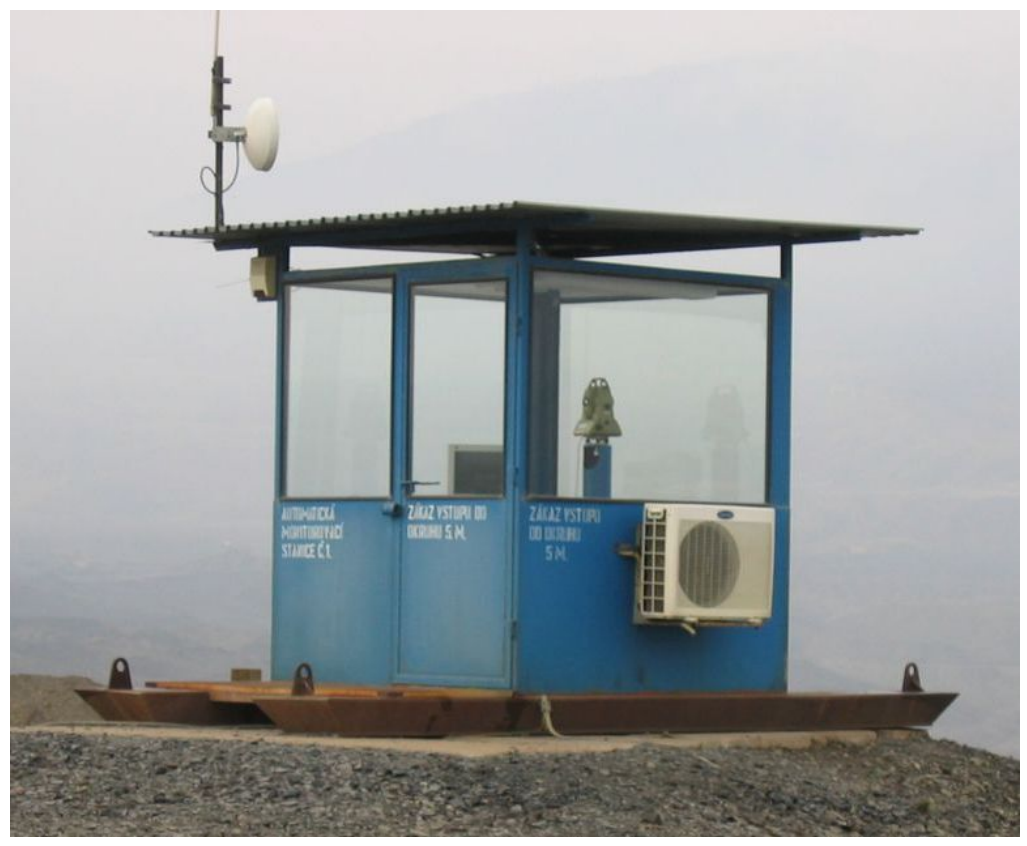

Figure 1: Total station in the protective shelter.

The monitoring system consists of several elements, the main element is the automatic total station Leica TCRA2003. Other elements of the monitoring system are observed points situated on the slopes of the Krušné mountains, reference points located on a technical objects on the opposite side of the mine and a management center. Reference points are located in stable area and no shifts are not expected. The total station is situated in solid soil in the middle of the mine in a protective metal shelter (see in Fig. 1) with windows made from ordinary glass. There is also heating and air conditioning for preservation optimal temperature in the shelter. Schematic situation of the total station and reference points is in Fig. 2.

Measurement of the observed and reference points is carried out in a time period of an hour. The measurement is repeated 365 days a year with the exception of service outages and periods when visibility is not sufficient.

The data sent to the management center are values measured by the total station (horizontal direction, zenith angle and slope distance) and also outside temperature and atmospheric

\footnotetext{
${ }^{1}$ Krušné mountains - mountains forming west boundary of The Czech republic with Germany, more: https://en.wikipedia.org/wiki/Ore_Mountains
} 


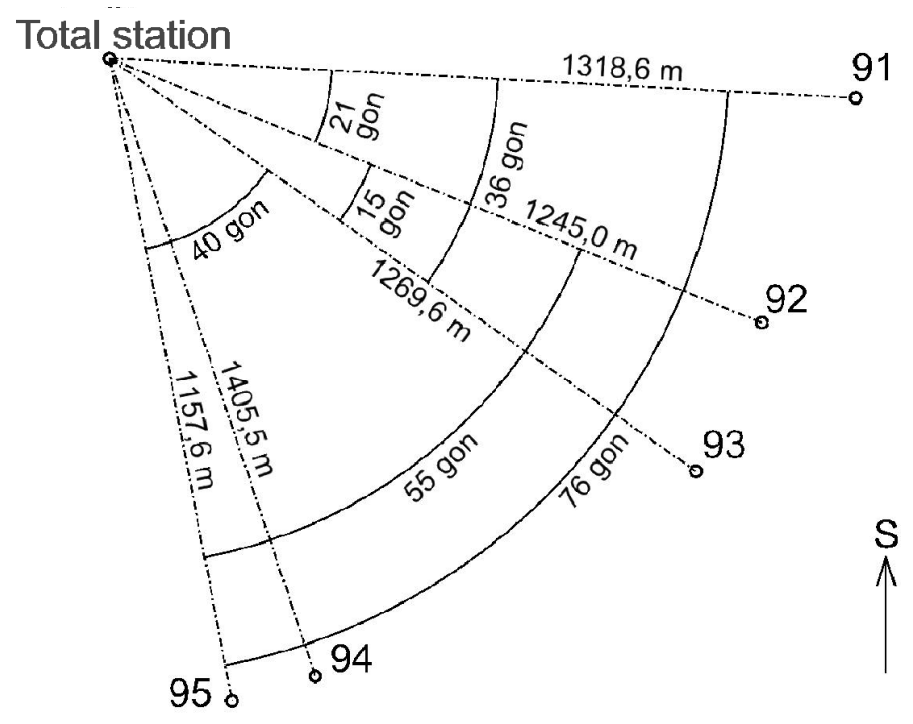

Figure 2: Schematic sketch of the situation of the instrument and ref. points.

pressure. Shifts of observed points are calculated immediately for each round of measurements and relevant employees of the company are informed by a SMS in the case of exceeding the limit values of shifts.

There is a detailed description of establishment of the monitoring system in [7].

The measured values used in an analysis described below cover time period from the beginning of the year 2006 to July 2010.

\section{Mathematical basis of the analysis of the variations of measured values}

Different methods (regression analysis, correlation analysis, discrete Fourier transform, etc.) were tested for the analysis of the variations of measured values, at the beginning. But at the end an approximation of measured values by a specific curve (L-H function) was selected as the best way. L-H function contains the linear and harmonic part and its equation is the following:

$$
y=a+b \cdot x+c \cdot \sin \left(\frac{x \cdot 2 \pi}{t}+d\right)
$$

where $a$ is an absolute coefficient, $b$ is a linear coefficient (slope of the regression), $c$ is an amplitude of the harmonics part, $d$ is a phase shift and $t$ is a period. The reason of the choice of this $\mathrm{L}-\mathrm{H}$ function was to indicate the linear trend and periodic changes in measured values concurrently. There is a basic assumption that the harmonic changes have annual period depending on air temperature and other weather conditions variations.

The coefficients of L-H function were calculated by the method of least squares. Daily averages of measured values were used in the calculation for a purpose of better stability of the calculation. This way of the calculation leads to an elimination of daily variations of 
measured values. Approximate unknowns were determined experimentally and to all daily averages were assigned the same weights.

After first approximations of daily averages of the horizontal direction the standard procedure of the calculation described above was changed. One more harmonic member was added to the equation 1 . So the final equation is then:

$$
y=a+b \cdot x+c \cdot \sin \left(\frac{x \cdot 2 \pi}{t_{1}}+d\right)+e \cdot \cos \left(\frac{x \cdot 2 \pi}{t_{2}}+f\right),
$$

where $e$ is an amplitude of the second harmonics part, $f$ is a phase shift and $t_{2}$ is a period of the second harmonics part.The calculation of an estimation of unknown coefficients is done in several steps, in which are unknown coefficients estimated in groups or independently. There are also applied weights of measurements, which are derived from calculated standard deviations of measurements in a previous step of the calculation. The least squares method was used for the estimation of the unknown coefficients as a basic calculation method, too.

The calculated linear coefficient of L-H function was tested by tests of statistical hypotheses. The tested hypothesis is none linear trend in measured data, namely whether the calculated coefficient $b$ corresponds to the expected values of $\Theta$. In this case, the premise is parameter $b$ has value $\Theta=0$. Null hypothesis will be of the form:

$$
H_{0}: b=\Theta \Rightarrow b=0 \text {. }
$$

Testing of statistical hypotheses can be done on the base of two test criteria. In the first case, the tested value $F$ has the Fisher distribution of probability with $(n-k)$ degrees of freedom

$$
F=\frac{(b-\Theta)^{2}}{\sigma_{b}^{2}} .
$$

In the second case, the tested value $T$ has the Student T-distribution of probability with $(n-k)$ degrees of freedom

$$
T=\frac{(b-\Theta)}{\sigma_{b}}
$$

Critical values for the $F_{\alpha}$ and $T_{\alpha / 2}$ is determined from Tables or calculation for two-sided test at significance level $\alpha$. We will reject the null hypothesis if $F>F_{\alpha}$ or $|T|>T_{\alpha / 2}$.

Finally, a comparison was made of daily averages of measurements and their L-H function and $\mathrm{L}-\mathrm{H}$ curve approximation of air temperature, which was determined by the same procedure as the $\mathrm{L}-\mathrm{H}$ function of measured values according to 1 . The premise of this comparison is a dependency of measured values on the changes of average air temperature during the year. The comparison was done only graphically.

The analysis was carried out for the reference points no. 91, 92, 93, 94 and 95 for the time period from January 2006 to July 2010. These points are all reference points which were or are measured by total station, observed points were not included in the analysis becouse of their possible movements.

Geoinformatics FCE CTU 15(1), 2016 


\section{Analysis of the air temperature variations}

A part of the monitoring system described above is a sensor for a measuring air temperature and air pressure. The measured values by this sensor are saved for each record of the measurements together with value of horizontal direction, zenith angle and slope distance.

Values of the recorded air temperature for measurements to reference point 93 were used in the analysis of the air temperature variations. The reason of using point 93 is the highest number of the measurements.

Analysis of the air temperature is based on an approximation of daily averages of air temperature by L-H function according the formula 1, because there is a presumption of only one significant annual period in measured temperature.

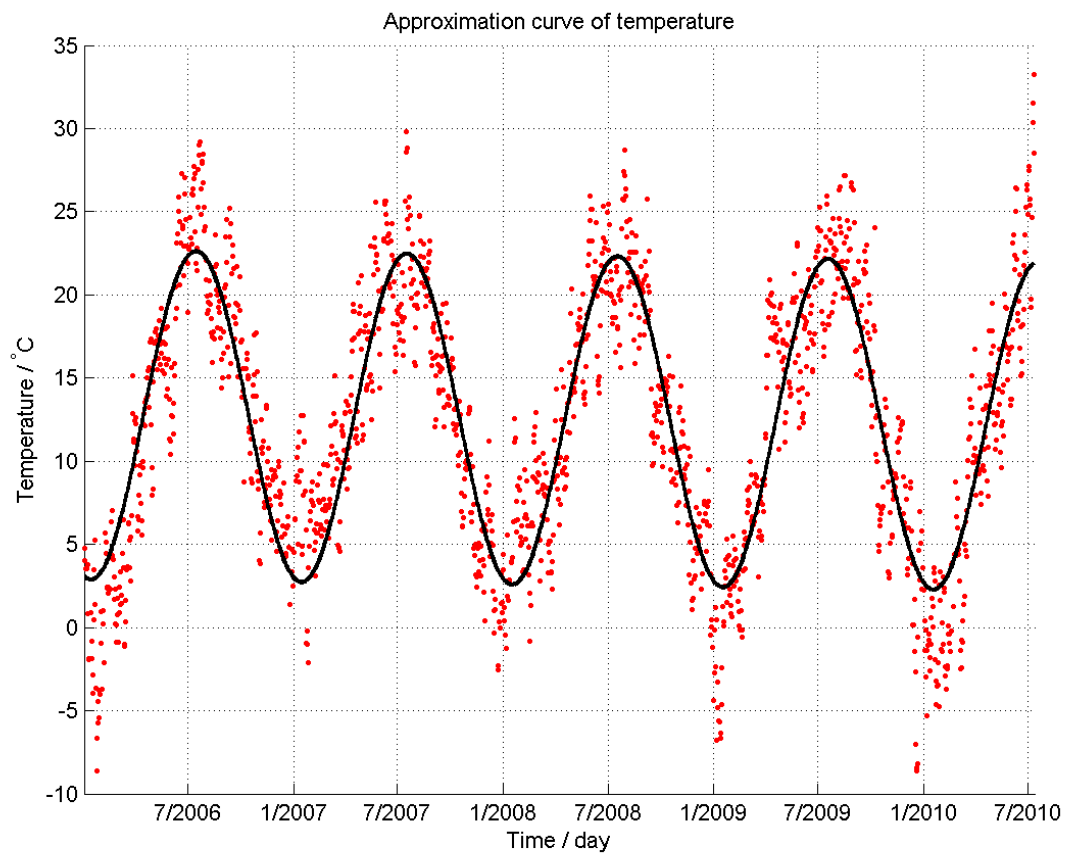

Figure 3: Aproximation curve of air temperature, reference point no. 93.

The result of the approximation can be seen in Fig. 3, the values of the significant coefficients of L-H function are listed in Table 1, where are listed calculated linear coefficient, amplitude and period.

As it follows from Fig. 3 and it was expected, temperature has a periodic progress with annual period and amplitude of $10^{\circ} \mathrm{C}$. Lower calculated amplitude is probably given by the daily averages (at night is cooler).

Approximation of daily averages of air temperature gives us value of linear trend $-15{ }^{\circ} \mathrm{C}$ per year. This slight decrease is visible in Fig. 3, but no specific conclusion can be done because of it is a short period of time for temperature. It is therefore appropriate to take this 
Table 1: Some calculated coefficients L-H function of air tempperature for point no. 93

\begin{tabular}{|c|c|c|c|c|}
\hline Point & Coefficient & Value & Coefficient & Value \\
\hline \multirow{4}{*}{93} & $B\left[\frac{{ }^{\circ} \mathrm{C}}{\mathrm{day}}\right]$ & $-4.16 \mathrm{E}-04$ & $c\left[{ }^{\circ} \mathrm{C}\right]$ & 9.91 \\
\cline { 2 - 5 } & $\sigma_{b}\left[\frac{\mathrm{o}}{\mathrm{d} d a y}\right]$ & $2.2 \mathrm{E}-08$ & $\sigma_{c}\left[{ }^{\circ} \mathrm{C}\right]$ & $1 \mathrm{E}-05$ \\
\cline { 2 - 5 } & $b\left[\frac{\mathrm{o}}{\text { year }}\right]$ & -0.15 & $t_{1}[$ day $]$ & 366.4 \\
\cline { 2 - 5 } & $\sigma_{b}\left[\frac{\mathrm{o}}{\text { year }}\right]$ & $8 \mathrm{E}-06$ & $\sigma_{t_{1}}[$ day $]$ & $5 \mathrm{E}-05$ \\
\hline
\end{tabular}

linear trend of temperature only as informative. The linear trend was not tested by tests of statistical hypotheses (3).

\section{Analysis of the horizontal direction variations}

The analysis of the horizontal direction was done according to the equation (2), which was used for an approximation of the data due to the large variance of measured data and the assumption of two important periods, which have been identified in the graphs of the measured values. Input data of the analysis were daily averages of measurements of the horizontal direction.

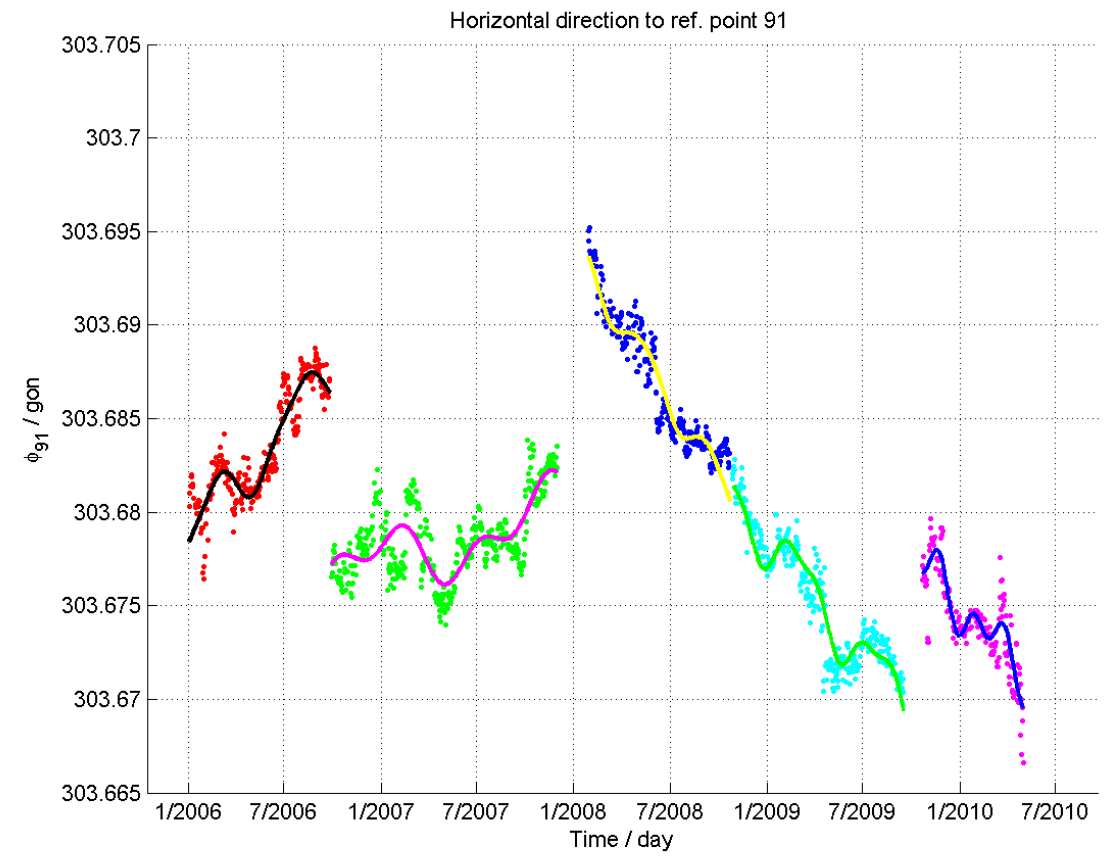

Figure 4: Approximation curve of horizontal direction, ref. point no. 91.

Another specific feature of the analysis of the horizontal direction is the need to separate the measured data to the time intervals in which is the same zero direction setting of the horizontal circle. These intervals have been created on the basis of knowledge of service outages and other discontinuities in the data. Finally, the most important 5 intervals were 


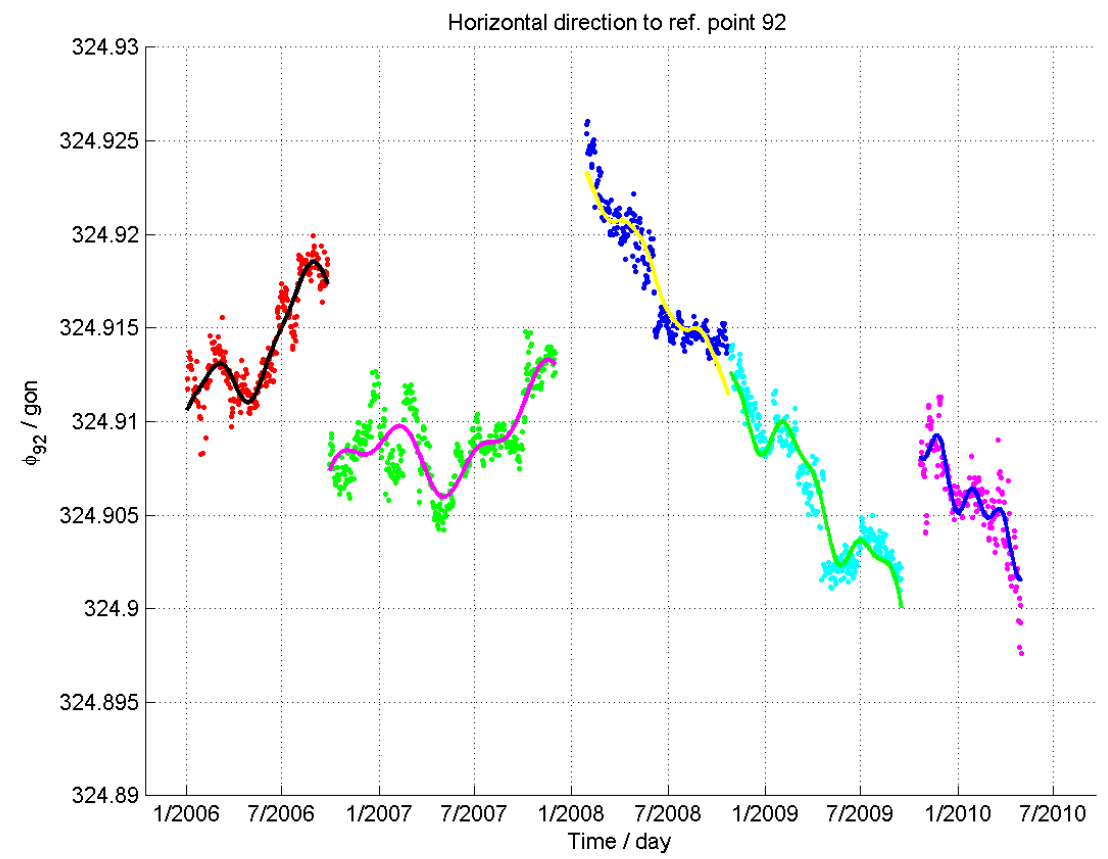

Figure 5: Approximation curve of horizontal direction, ref. point no. 92.

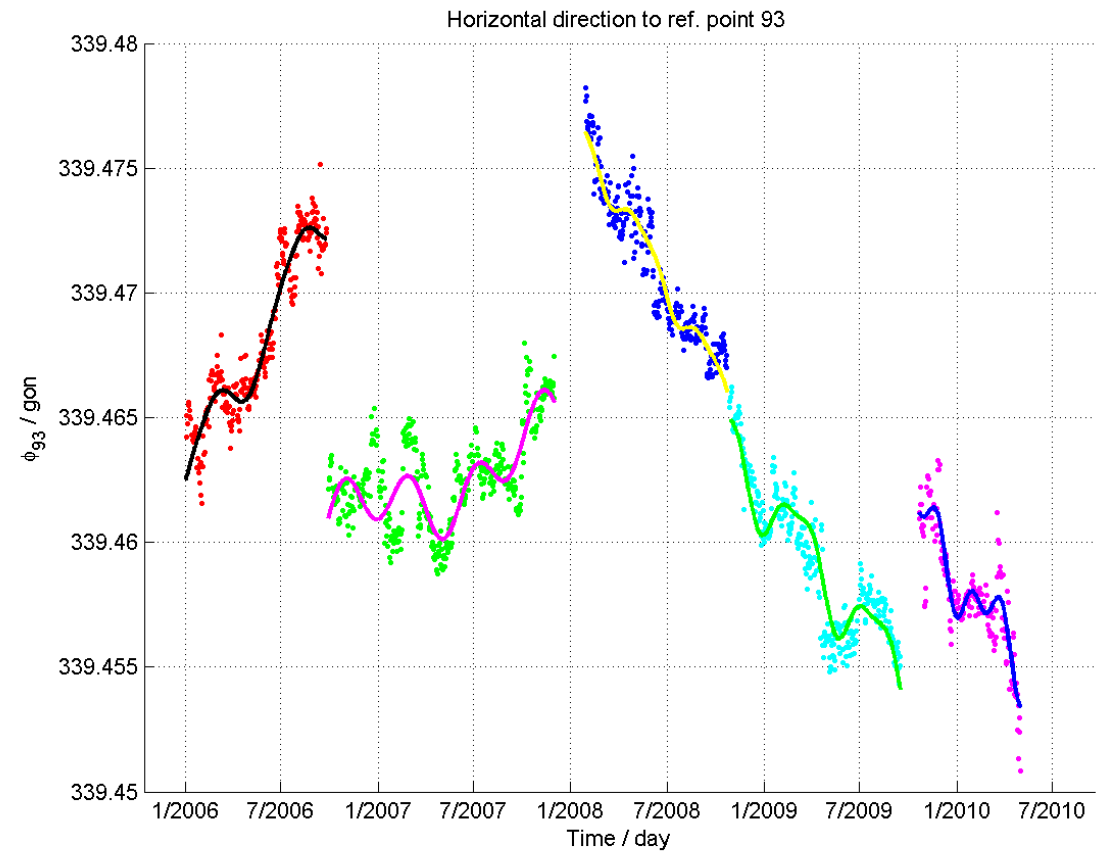

Figure 6: Approximation curve of horizontal direction, ref. point no. 93. 
Table 2: Selected time intervals

\begin{tabular}{|c|c|c|c|}
\hline Interval number & Beginning of interval & End of interval & Number of days \\
\hline 1 & 2.1 .2006 & 26.9 .2006 & 267.0 \\
\hline 2 & 29.9 .2006 & $30.11 .200710: 00$ & $427 ., 4$ \\
\hline 3 & 28.1 .2008 & 23.10 .2008 & 269.0 \\
\hline 4 & 27.10 .2008 & $16.9 .200912: 00$ & 324.5 \\
\hline 5 & $21.10 .200911: 00$ & 2.5 .2010 & 192.5 \\
\hline
\end{tabular}

selected, which are listed in the Table 2 .

The results of the approximations for the reference points No. 91, 92 and 93 are graphically represented in Fig. 4, 5 and 6. There are approximation curves for all tested intervals in the charts. The values of linear trend are listed in Table 3 and Table 4 shows the calculated size of the time periods for the time intervals. The last Table 5 contains the results of the tests of statistical hypotheses about the linear trend.

Table 3: Values of linear trend of horizontal direction

\begin{tabular}{|c|c|c|c|c|c|c|}
\hline \multirow{2}{*}{ Ref. point } & \multirow{2}{*}{ Coefficient } & \multicolumn{5}{|c|}{ Time interval number } \\
\cline { 2 - 7 } & & $\mathbf{1}$ & $\mathbf{2}$ & $\mathbf{3}$ & $\mathbf{4}$ & $\mathbf{5}$ \\
\hline \multirow{2}{*}{$\mathbf{9 1}$} & $b\left[\frac{\text { mgon }}{\text { month }}\right]$ & 0.99 & 0.25 & -1.35 & -1.04 & -0.90 \\
\cline { 2 - 7 } & $\sigma_{b}\left[\frac{\text { mgon }}{\text { month }}\right]$ & 0.02 & 0.04 & 0.02 & 0.01 & 0.04 \\
\hline \multirow{2}{*}{$\mathbf{9 2}$} & $b\left[\frac{\text { mgon }}{\text { month }}\right]$ & 0.85 & 0.28 & -1.31 & -1.15 & -0.88 \\
\cline { 2 - 7 } & $\sigma_{b}\left[\frac{\text { mgon }}{\text { month }}\right]$ & 0.02 & 0.02 & 0.02 & 0.02 & 0.04 \\
\hline \multirow{2}{*}{$\mathbf{9 3}$} & $b\left[\frac{\text { mgon }}{\text { month }}\right]$ & 1.19 & 0.27 & -1.13 & -0.85 & -0.92 \\
\cline { 2 - 7 } & $\sigma_{b}\left[\frac{\text { mgon }}{\text { month }}\right]$ & 0.02 & 0.01 & 0.02 & 0.01 & 0.03 \\
\hline \multirow{2}{*}{$\mathbf{9 4}$} & $b\left[\frac{\text { mgon }}{\text { month }}\right]$ & 0.97 & 0.07 & & & \\
\cline { 2 - 7 } & $\sigma_{b}\left[\frac{\text { mgon }}{\text { mésic }}\right]$ & 0.02 & 0.06 & & & \\
\hline \multirow{2}{*}{$\mathbf{9 5}$} & $B\left[\frac{\text { mgont }}{\text { month }}\right]$ & & 0.85 & -1.27 & -1.00 & -0.86 \\
\cline { 2 - 7 } & $\sigma_{b}\left[\frac{\text { mgon }}{\text { month }}\right]$ & & 0.04 & 0.02 & 0.01 & 0.03 \\
\hline
\end{tabular}

The results listed in Table 3 show, that linear coefficient is positive in the first two time intervals and negative in the other intervals. The reason for this is not clear, but probably the change was caused by an adjusting the fixing of the total station or a reparation of the instrument.

The sizes of the linear changes are around $1 \mathrm{mgon} / \mathrm{month}$ in all time intervals. This value is high and definitely negligible. Tests of statistical hypotheses have been made on the significance level $\alpha=5 \%$ in the both ways of calculation (4) and (5). All results of the tests except the $2^{\text {nd }}$ time interval for the point 94 are the same, the null hypothesis is rejected.

Based on these results and tests carried out, we can declare a linear trend in the data found for proven. Sizes of calculated linear coefficients are similar in comparing the calculated values for various reference points in the same time interval, therefore it can be assumed, that the calculated horizontal angles are deprived of this influence of linear trend.

The cause of the linear trend of the measured data is most likely to be found in its way of measuring the total station, when the instrument measure only in the first face of the 
Table 4: Values of calculated period for horizontal direction

\begin{tabular}{|c|c|c|c|c|c|c|}
\hline \multirow{2}{*}{ Ref. point } & \multirow{2}{*}{ Coeffiecient } & \multicolumn{6}{|c|}{ number of time interval } \\
\cline { 2 - 7 } & & $\mathbf{1}$ & $\mathbf{2}$ & $\mathbf{3}$ & $\mathbf{4}$ & $\mathbf{5}$ \\
\hline \multirow{4}{*}{$\mathbf{9 1}$} & $t_{1}[$ day $]$ & 163 & 323 & 123 & 152 & 119 \\
\cline { 2 - 7 } & $\sigma_{t_{1}}[$ day $]$ & 3 & 22 & 3 & 2 & 4 \\
\cline { 2 - 7 } & $t_{2}[$ day $]$ & 84 & 137 & 67 & 72 & 62 \\
\cline { 2 - 7 } & $\sigma_{t_{2}}[$ day $]$ & 4 & 3 & 11 & 1 & 1 \\
\hline \multirow{4}{*}{92} & $t_{1}[$ day $]$ & 185 & 324 & 130 & 158 & 106 \\
\cline { 2 - 7 } & $\sigma_{t_{1}}[$ day $]$ & 3 & 10 & 3 & 2 & 4 \\
\cline { 2 - 7 } & $t_{2}[$ day $]$ & 85 & 134 & 49 & 73 & 60 \\
\cline { 2 - 7 } & $\sigma_{t_{2}}[$ day $]$ & 3 & 2 & 3 & 1 & 1 \\
\hline \multirow{4}{*}{93} & $t_{1}[$ day $]$ & 164 & 352 & 126 & 145 & 126 \\
\cline { 2 - 7 } & $\sigma_{t_{1}}[$ day $]$ & 3 & 14 & 3 & 1 & 3 \\
\cline { 2 - 7 } & $t_{2}[$ day $]$ & 82 & 126 & 62 & 73 & 61 \\
\cline { 2 - 7 } & $\sigma_{t_{2}}[$ day $]$ & 7 & 1 & 2 & 1 & 1 \\
\hline \multirow{5}{*}{94} & $t_{1}[$ day $]$ & 172 & 84 & & & \\
\cline { 2 - 7 } & $\sigma_{t_{1}}[$ day $]$ & 3 & 3 & & & \\
\cline { 2 - 7 } & $t_{2}[$ day $]$ & 86 & 19 & & & \\
\cline { 2 - 7 } & $\sigma_{t_{2}}[$ day $]$ & 5 & 0.5 & & & \\
\hline \multirow{4}{*}{95} & $t_{1}[$ day $]$ & & 148 & 120 & 148 & 124 \\
\cline { 2 - 7 } & $\sigma_{t_{1}}[$ day $]$ & & 5 & 2 & 2 & 3 \\
\cline { 2 - 7 } & $t_{2}[$ day $]$ & & 54 & 66 & 72 & 61 \\
\cline { 2 - 7 } & $\sigma_{t_{2}}[$ day $]$ & & 8 & 7 & 1 & 1 \\
\hline
\end{tabular}

telescope. So the total station rotates in a clockwise direction only. It is therefore possible that this rotary motion there is a gradual tightening or loosening of total station.

The Table 4 contains the calculated periods. It can confirm that the measured values of the horizontal direction change for all reference points in the same way. This conclusion is confirmed by the graphs in Fig. 4, 5 and 6 .

It is impossible to detect periodic phenomenon in the measured data, because any specific period does not repeat more than once. So, we must assume that the measured data of the horizontal direction do not contain any periodic changes that we could guess from these time intervals.

The next step of the analysis of the horizontal direction is the comparison of the development of the horizontal direction and the air temperature. The easiest way to compare these two variables is the comparison of the approximation curves in one graph. This procedure will create a graph that is in Fig. 7, where is not evident a clear dependency measured values of the horizontal direction and air temperature. Still, it can be assumed that all or most of the relevant variables affecting the measured value of the horizontal direction is also in some way dependent on the temperature (refraction, the curvature of the glass in windows of the shelter, etc.). This comparison was made only for measurements to reference point no. 93, because measured values of the horizontal direction to other reference points are considerably similar. 
Table 5: Results of statistical hypothesis

\begin{tabular}{|c|c|c|c|c|c|c|}
\hline \multirow{2}{*}{ Ref. point } & \multirow{2}{*}{ Coeffiecient } & \multicolumn{5}{|c|}{ number of time interval } \\
\hline & & 1 & 2 & 3 & 4 & 5 \\
\hline \multirow{5}{*}{91} & $F$ & 2010 & 47 & 6257 & 5332 & 633 \\
\hline & $F_{\alpha=0,5}$ & 4 & 4 & 4 & 4 & 4 \\
\hline & $T$ & 45 & 6,9 & -79 & -73 & -25 \\
\hline & $T_{\alpha=0,25}$ & 2 & 2 & 2 & 2 & 2 \\
\hline & $n^{\prime}$ & 250 & 410 & 261 & 311 & 157 \\
\hline \multirow{5}{*}{92} & $F$ & 1598 & 182 & 3657 & 4962 & 570 \\
\hline & $F_{\alpha=0,5}$ & 4 & 4 & 4 & 4 & 4 \\
\hline & $T$ & 40 & 14 & -60 & -70 & -24 \\
\hline & $T_{\alpha=0,25}$ & 2 & 2 & 2 & 2 & 2 \\
\hline & $n^{\prime}$ & 249 & 411 & 260 & 313 & 172 \\
\hline \multirow{5}{*}{93} & $F$ & 3133 & 433 & 4638 & 3727 & 788 \\
\hline & $F_{\alpha=0,5}$ & 4 & 4 & 4 & 4 & 4 \\
\hline & $T$ & 56 & 21 & -68 & -61 & -28 \\
\hline & $T_{\alpha=0,25}$ & 2 & 2 & 2 & 2 & 2 \\
\hline & $n^{\prime}$ & 253 & 410 & 261 & 314 & 177 \\
\hline \multirow{5}{*}{94} & $F$ & 2131 & 1 & & & \\
\hline & $F_{\alpha=0,5}$ & 4 & 4 & & & \\
\hline & $T$ & 46 & 1 & & & \\
\hline & $T_{\alpha=0,25}$ & 2 & 2 & & & \\
\hline & $n^{\prime}$ & 250 & 127 & & & \\
\hline \multirow{5}{*}{95} & $F$ & & 548 & 5625 & 4604 & 742 \\
\hline & $F_{\alpha=0,5}$ & & 4 & 4 & 4 & 4 \\
\hline & $T$ & & 23 & -75 & -68 & -27 \\
\hline & $T_{\alpha=0,25}$ & & 2 & 2 & 2 & 2 \\
\hline & $n^{\prime}$ & & 203 & 261 & 315 & 165 \\
\hline
\end{tabular}

The conclusion of the analysis of the horizontal direction is clear, measured values of the horizontal direction include many random and systematic errors, which cause a large variance of measured values. These errors are caused with the highest probability by a combination of effects of temperature, insolation and the construction of the protective shelter.

The total station measures over ordinary glass, which is set into the metal walls of the protective shelter. Due to an influence of insolation and temperature windows of the shelter change their optical behavior.

The results of the approximations of L-H features show that the measured data contain linear trend of a considerable size, on average, $1 \mathrm{mgon} / \mathrm{month}$. The cause of this trend is probably in the technology of measurement, when the instrument measures only in the first face of a telescope.

Man cannot draw a clear conclusion about periods obtained by this analysis in the measured values, because the period was not found, which occurs more often at different time intervals.

From the comparison of temperature and the values of the horizontal direction is clear that 


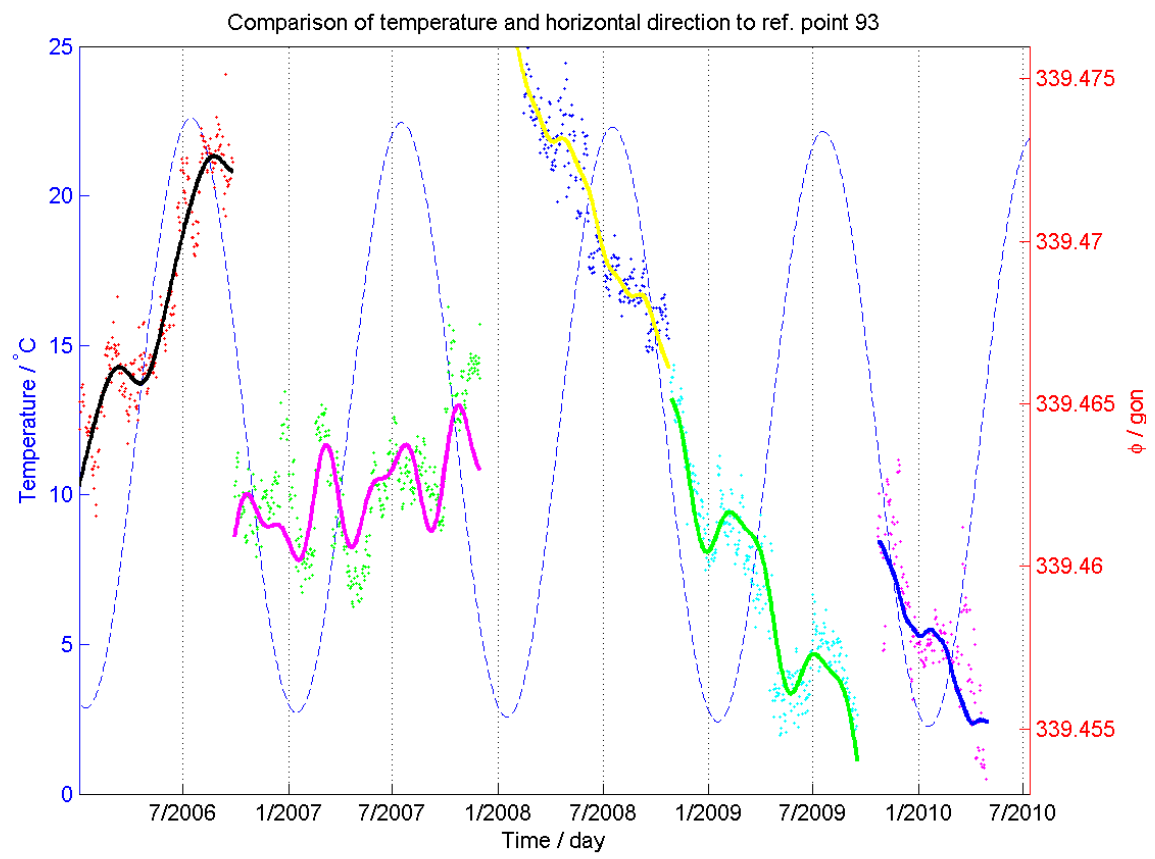

Figure 7: Comparison of approx. curves of horizontal direction and temperature, ref. point no. 93.

values of the horizontal direction do not correspond to the temperature hardly over. So, there is not a clear dependency between these variables.

The analysis of the horizontal direction but also brought a positive conclusion, too. Changes in the measured data to different reference points are similar and therefore the horizontal angle should be stripped of their influence.

\section{Analysis of the variations of the horizontal angle}

As mentioned in the previous part, the calculation of horizontal angles from measured values of the horizontal direction should remove most adverse errors in measured values. So, the variance of the calculated values of the horizontal angle should not achieve such values as for the horizontal directions. Another advantage is the possibility to calculate an approximation of all the measurements from January 2006 to July 2010, therefore it is not necessary to divide the measurements to intervals as in the case of the horizontal direction.

The analysis was performed daily averages approximation of horizontal angles by L-H function with one harmonic member (1). Similarly as in the analysis of the horizontal direction the calculated linear coefficients were tested the tests of statistical hypotheses, whether they are equal to zero. The comparison of values of the horizontal angles and values of air temperature was made at the end of the analysis.

Measurements to reference point no. 94 were not used in the analysis, because it was measured 
for a short time to this point. From measurements to other reference points were calculated the angles (all combinations) $\omega_{93-91}, \omega_{93-92}, \omega_{92-91}, \omega_{95-93}, \omega_{95-92}$ and $\omega_{95-91}$. In this case was deliberately violated the conventions of marking horizontal angles in geodesy, as the first point is marked the right arm angle. The schematic situation of the total station and reference points is in Fig. 2.

Graphic presentation of the results of the approximation can be seen in the following figures 8 and 9, where is well seen, that the calculation of the horizontal angle remove undesirable influences and the progress of the measured values is periodic. The variance of the values is significantly smaller than the variance of the horizontal direction. A size of the variance is from 0.5 to 1 mgon for daily averages. It is also apparent from the figures that the data contain a small linear trend.

Table 6: Significant coefficients of L-H function calculated in approximation of horizontal angles

\begin{tabular}{|c|c|c|c|c|}
\hline Angle & Coefficient & Value & Coefficient & Value \\
\hline \multirow{4}{*}{$\omega_{9291}$} & $t_{1}[d a y]$ & 373.7 & $b\left[\frac{g o n}{d a y}\right]$ & $5.7 \mathrm{E}-07$ \\
\hline & $\sigma_{t_{1}}[d a y]$ & 1.5 & $\overline{\sigma_{b}\left[\frac{g o n}{d a y}\right]}$ & $1 \mathrm{E}-08$ \\
\hline & $c[$ mgon $]$ & 0.32 & $b\left[\frac{m g o n}{\text { year }}\right]$ & 0.205 \\
\hline & $\sigma_{c}[m g o n]$ & 0.01 & $\sigma_{b}\left[\frac{m g o n}{\text { year }}\right]$ & 0.005 \\
\hline \multirow{4}{*}{$\omega_{9391}$} & $t_{1}[d a y]$ & 362.6 & $b\left[\frac{\text { gon }}{\text { day }}\right]$ & $-3.3 \mathrm{E}-07$ \\
\hline & $\sigma_{t_{1}}[d a y]$ & 0.8 & $\sigma_{b}\left[\frac{g o n}{d a y}\right]$ & $1 \mathrm{E}-08$ \\
\hline & $c[$ mgon $]$ & 0.63 & $b\left[\frac{m g o n}{\text { year }}\right]$ & -0.120 \\
\hline & $\sigma_{c}[$ mgon $]$ & 0.01 & $\sigma_{b}\left[\frac{m \text { mon }}{\text { year }}\right]$ & 0.005 \\
\hline \multirow{4}{*}{$\omega_{9392}$} & $t_{1}[d a y]$ & 366.2 & $b\left[\frac{\text { gon }}{\text { day }}\right]$ & $-9.0 \mathrm{E}-07$ \\
\hline & $\sigma_{t_{1}}[d a y]$ & 0.5 & $\sigma_{b}\left[\frac{g o n}{d a y}\right]$ & 2E-08 \\
\hline & $c[$ mgon $]$ & 1.01 & $b\left[\frac{\text { mgon }}{\text { year }}\right]$ & -0.326 \\
\hline & $\sigma_{c}[$ mgon $]$ & 0.01 & $\sigma_{b}\left[\frac{m \text { mon }}{\text { year }}\right]$ & 0.006 \\
\hline \multirow{4}{*}{$\omega_{9591}$} & $t_{1}[d a y]$ & 359.8 & $b\left[\frac{\text { gon }}{\text { day }}\right]$ & $-2.4 \mathrm{E}-07$ \\
\hline & $\sigma_{t_{1}}[d a y]$ & 3.0 & $\sigma_{b}\left[\frac{g o n}{d a y}\right]$ & $1 \mathrm{E}-08$ \\
\hline & $c[$ mgon $]$ & 0.15 & $b\left[\frac{\text { mgon }}{\text { year }}\right]$ & -0.086 \\
\hline & $\sigma_{c}[$ mgon $]$ & 0.01 & $\sigma_{b}\left[\frac{m g o n}{\text { year }}\right]$ & 0.005 \\
\hline \multirow{4}{*}{$\omega_{9592}$} & $t_{1}[d a y]$ & 381.7 & $b\left[\frac{\text { gon }}{\text { day }}\right]$ & $-1.2 \mathrm{E}-06$ \\
\hline & $\sigma_{t_{1}}[d a y]$ & 1.5 & $\sigma_{b}\left[\frac{g o n}{d a y}\right]$ & $2 \mathrm{E}-08$ \\
\hline & $c[$ mgon $]$ & 0.50 & $b\left[\frac{\text { mgon }}{\text { year }}\right]$ & -0.435 \\
\hline & $\sigma_{c}[m g o n]$ & 0.01 & $\sigma_{b}\left[\frac{m g o n}{\text { year }}\right]$ & 0.007 \\
\hline \multirow{4}{*}{$\omega_{9593}$} & $t_{1}[d a y]$ & 369.8 & $b\left[\frac{\text { gon }}{\text { day }}\right]$ & $-6.0 \mathrm{E}-07$ \\
\hline & $\sigma_{t_{1}}[d a y]$ & 1.0 & $\sigma_{b}\left[\frac{g o n}{d a y}\right]$ & 1E-08 \\
\hline & $c[$ mgon $]$ & 0.43 & $b\left[\frac{\text { mgon }}{\text { year }}\right]$ & -0.218 \\
\hline & $\sigma_{c}[$ mgon $]$ & 0.01 & $\sigma_{b}\left[\frac{m g o n}{\text { year }}\right]$ & 0.005 \\
\hline
\end{tabular}

The results in Table 6 show that the values of the horizontal angle oscillate approximately with annual period and have average amplitude of 0.5 mgon. It can be assumed that this periodic progress with an annual period is caused by periodic changes of air temperature 


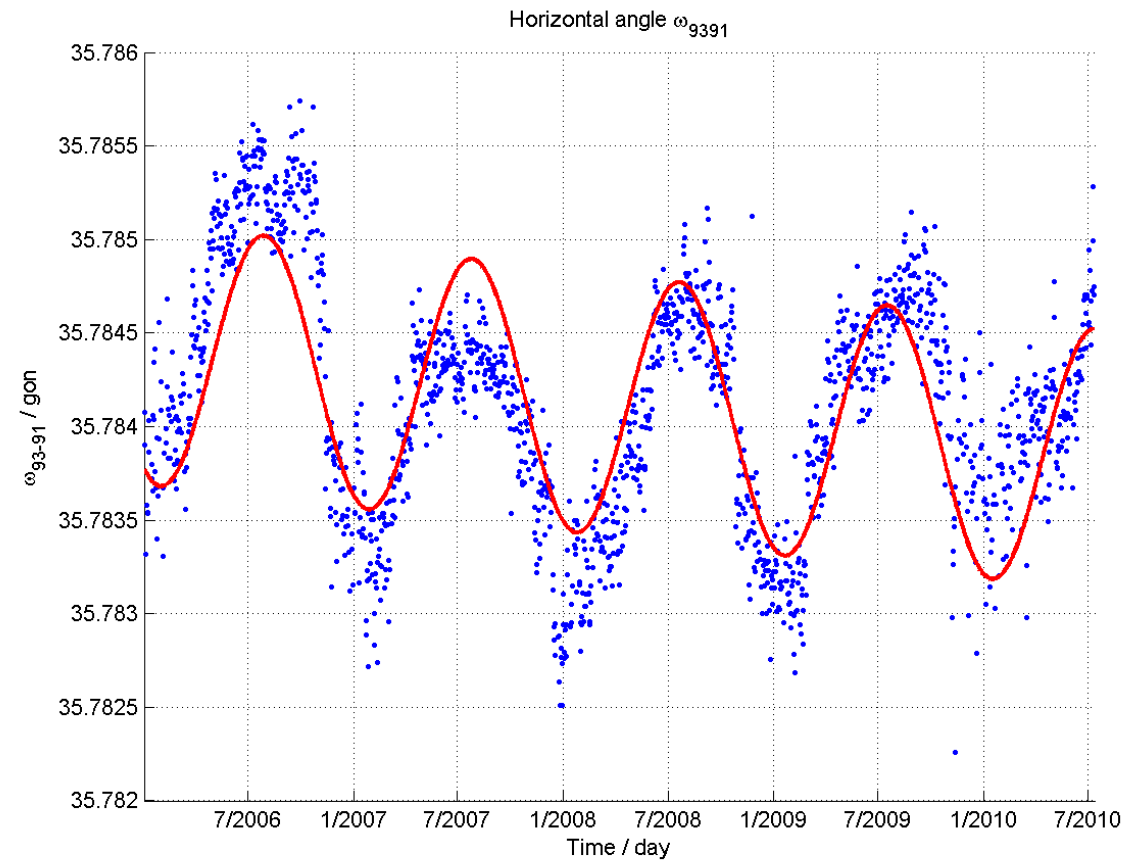

Figure 8: Approximation curve of the horizontal angle between ref. points no. 93 and 91.

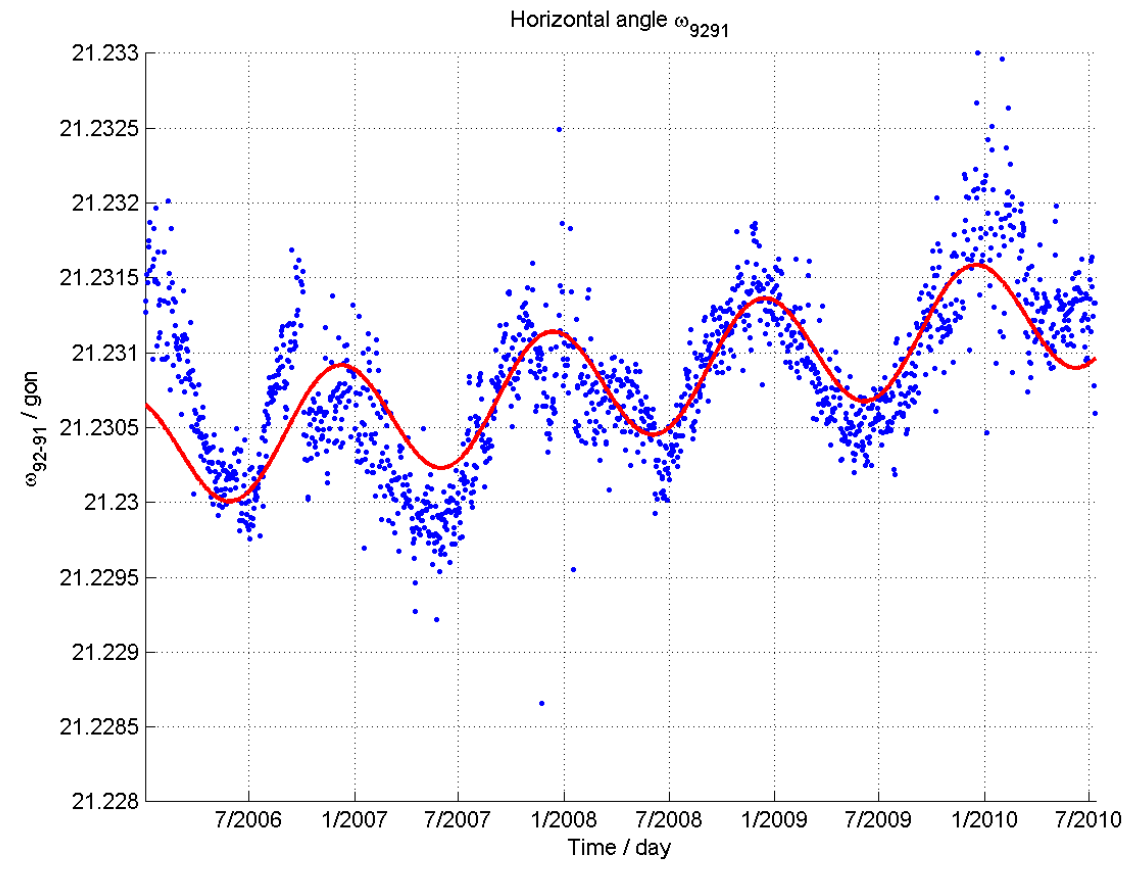

Figure 9: Approximation curve of the horizontal angle between ref. points no. 92 and 91. 
Table 7: Results of the tests of statistical hypotheses of linear trend of horizontal angle.

\begin{tabular}{|c|c|c|c|c|c|}
\hline Angle & $\mathbf{F}$ & $\mathbf{F}_{\alpha=\mathbf{0 . 5}}$ & $\mathbf{T}$ & $\mathbf{T}_{\alpha=\mathbf{0 . 2 5}}$ & $\mathbf{n}^{\prime}$ \\
\hline$\omega_{\mathbf{9 2 9 1}}$ & 301047 & 4 & 549 & 2 & 1575 \\
\hline$\omega_{\mathbf{9 3 9 1}}$ & 24002 & 4 & -352 & 2 & 1577 \\
\hline$\omega_{\mathbf{9 3 9 2}}$ & 110396 & 4 & -332 & 2 & 1595 \\
\hline$\omega_{\mathbf{9 5 9 1}}$ & 309314 & 4 & -556 & 2 & 1100 \\
\hline$\omega_{\mathbf{9 5 9 2}}$ & 258677 & 4 & -509 & 2 & 1119 \\
\hline$\omega_{\mathbf{9 5 9 3}}$ & 81487 & 4 & -285 & 2 & 1126 \\
\hline
\end{tabular}

during the year. Comparison of temperature and the values of the horizontal angle will be described below. The periodic progress of the values of the horizontal angle can be assumed for proven.

The size of the calculated linear coefficients for reference points is an average $0.2 \mathrm{mgon} /$ year, and in addition the angle $\omega_{92-91}$ has a negative sign. Tests of statistical hypothesis were made in the same way as in the case of analysis of the horizontal direction of the tested hypothesis about zero directive of the regression line. The null hypothesis is rejected at all angles and thus a linear trend was proven. The numeric value of the results of the tests of statistical hypotheses are listed in Table 7. Despite the rejected of the null hypothesis the linear trend can be neglected on a base of its size and the required accuracy of measurement for this particular situation.

Furthermore, a next comparison was made of the calculated horizontal angles and their approximation curves with the temperature curve in the same way as in the previous chapter.

If the approximation curve of the air temperature is drawn in the one figure with the approximation curve of the horizontal angle it is created a graph suitable for comparison of these two variables. This graph is in the Fig. 10, which is a comparison of the approximation curve of the air temperature and horizontal angle $\omega_{93-91}$. It is clear from the figure that the size of the horizontal angle changes periodically depending on the air temperature. Specifically, this angle $\omega_{93-91}$ increases with increasing temperature and decreases with decreasing temperature. A very similar progress is in graphs of the comparison of the other horizontal angles with the air temperature.

Analysis of the horizontal angles brought interesting results. Periodic progress of values of horizontal angle was proved with an annual period and amplitude of 0.5 mgon. The obtained linear trend is so small that it can be neglected. It is seen from the all graphs with values of the horizontal angle that the calculation of the horizontal angles reduces almost all systematic errors that were observed in the values of the horizontal direction. Only random errors stay in data that cause the variance of the values of the horizontal angle visible in graphs.

Furthermore, a comparison of the horizontal angles and air temperature was made graphically. This comparison shows the annual progress of the horizontal angle corresponds to the annual progress of temperature. Man can conclude that periodic changes of the horizontal angle detected by analysis are most likely caused by the influence of temperature changes during the year. 


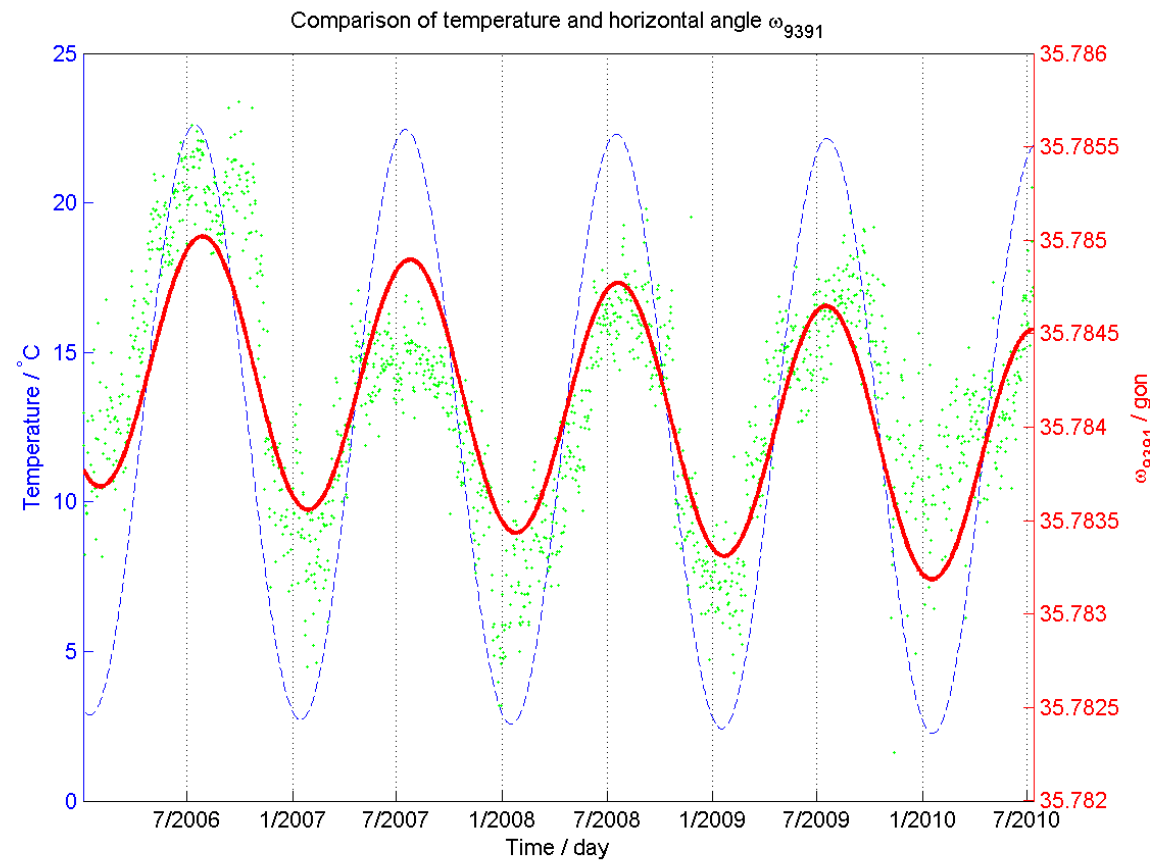

Figure 10: Comparison of approx. curves of horizontal angle and temperature, ref. points no. 93 and 91 .

\section{Analysis of the variations of the measured values of the zenith angle}

The next tested measured value is zenith angle. This analysis was made in the same way as the horizontal angle. Analysis was performed for all the measurements for the entire period of time, in which the data are available. Due the forced centering the position of the total station, the position of the instrument does not change and the height of the instrument varies very little. If we consider a value of $0.01 \mathrm{~m}$ as the extreme value of the height change of the instrument then the measured zenith angle to the nearest reference point no. $95(1157 \mathrm{~m})$ will change about 0.55 mgon. The value from the perspective of the long-term analysis and variance of measured values is negligible.

Only measured data to the reference point no. 92 was not included in the analysis for the first 11 months of measuring, because there is a big jump in the measured values for some unknown reason.

The analysis was performed in the same way as the analysis of the horizontal angle. There was used equation (1) for an approximation again, because only one main period is expected in measured data. There were used daily averages of measured values of the zenith angle in the calculation of the coefficients of L-H function. The final linear coefficients were tested by the tests of statistical hypothesis with the null hypothesis, that the linear trend is null.

The important coefficients of L-H functions are listed in Table 8, where are for all reference points calculated values of linear coefficient (linear trend), amplitude and period including 


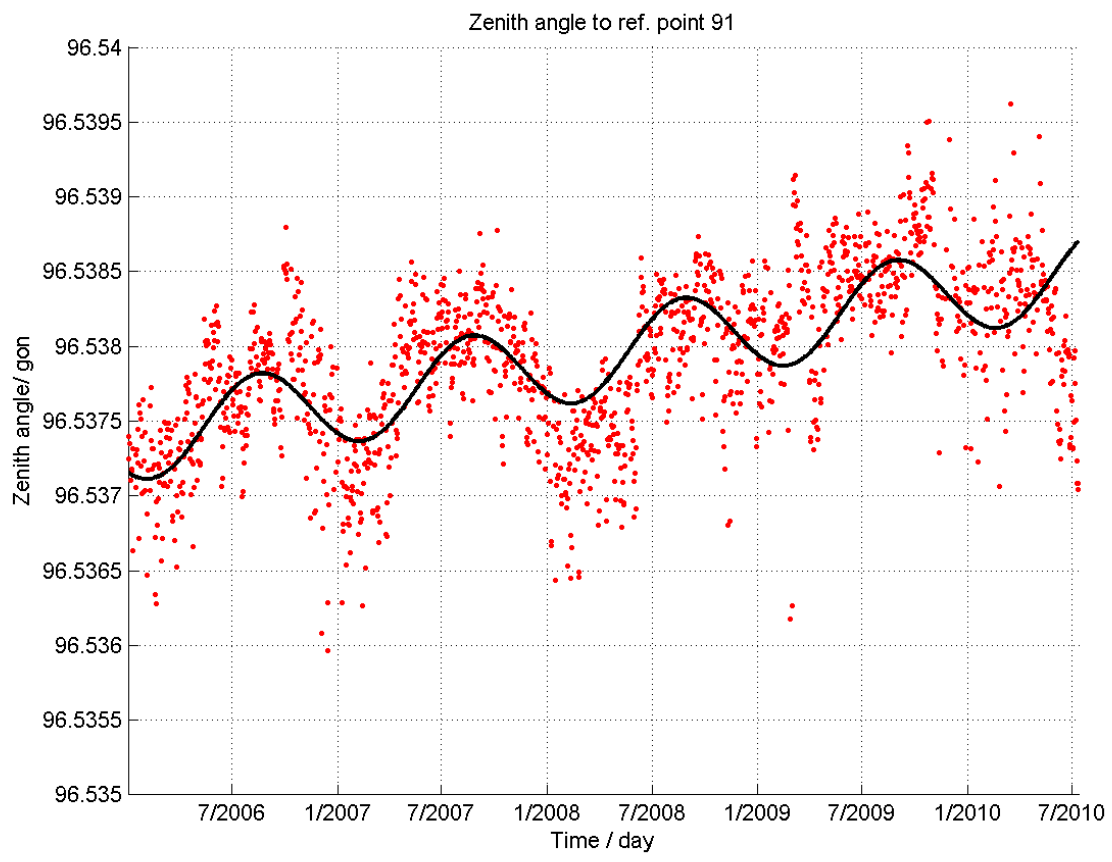

Figure 11: Approximation curve of zenith angle, ref. point no. 91.

their standard deviations.

An approximately annual period follows from the resulting values in addition to reference point no. 95, where was released 2.5-year period. The annual period should again point to a dependency on the change of air temperature. It is interesting that for all reference points can be observed a decrease in measured values at the end of the time period, but it is not clear the cause of the phenomenon.

There is also important result that the variance of the daily averages is $1 \mathrm{mgon}$ and the calculated amplitudes are significantly smaller. The smallest variance of values of daily averages has a zenith angle to the reference point no. 93, which was expected. Reference point no. 93 has the best stabilization in terms of spatial stability (a prism on the low metal bar) comparatively to other reference points (prisms on the lattice towers). Anyway, the variance of the daily averages is small for all reference points, which shows that the largest fluctuations of the measured values are caused by changes in the weather conditions during the day.

The values of the linear trend shown in the Table 8 are small. The results of the tests of statistical hypotheses are shown in Table 9 and the null hypothesis is rejected for all reference points, but the linear trend can be neglected on the basis of accuracy of measurements.

The measured values of the zenith angle to reference points were also compared with the measured values of the air temperature in a similar way as the horizontal directions and horizontal angles.

The comparison was made by graphical comparing of the approximation curve of temperature 
Table 8: Significant coefficients of L-H function calculated in approximation of zenith angles.

\begin{tabular}{|c|c|c|c|c|}
\hline Ref. point & Coefficient & Value & Coefficient & Value \\
\hline \multirow{4}{*}{91} & $b\left[\frac{g o n}{d a y}\right]$ & $6.84 \mathrm{E}-07$ & $c[$ gon $]$ & $2.9 \mathrm{E}-04$ \\
\hline & $\sigma_{b}\left[\frac{g o n}{d a y}\right]$ & 1E-09 & $\sigma_{c}[$ gon $]$ & $6 \mathrm{E}-07$ \\
\hline & $b\left[\frac{\text { mgon }}{\text { year }}\right]$ & 0.25 & $t[d a y]$ & 368.9 \\
\hline & $\sigma_{b}\left[\frac{\text { mgon }}{\text { year }}\right]$ & $4 \mathrm{E}-04$ & $\sigma_{t}[d a y]$ & 0.1 \\
\hline \multirow{4}{*}{92} & $b\left[\frac{\text { gon }}{d a y}\right]$ & 1.90E-07 & $c[$ gon $]$ & $2.8 \mathrm{E}-04$ \\
\hline & $\sigma_{b}\left[\frac{g o n}{d a y}\right]$ & $8 \mathrm{E}-10$ & $\sigma_{c}[$ gon $]$ & $4 \mathrm{E}-07$ \\
\hline & $b\left[\frac{\text { mgon }}{\text { year }}\right]$ & 0.07 & $t[d a y]$ & 374.9 \\
\hline & $\sigma_{b}\left[\frac{\text { mgon }}{\text { year }}\right]$ & $3 \mathrm{E}-04$ & $\sigma_{t}[d a y]$ & 0.1 \\
\hline \multirow{4}{*}{93} & $b\left[\frac{g o n}{d a y}\right]$ & $5.10 \mathrm{E}-07$ & $c[$ gon $]$ & $2.3 \mathrm{E}-04$ \\
\hline & $\overline{\sigma_{b}\left[\frac{g o n}{d a y}\right]}$ & $2 \mathrm{E}-09$ & $\sigma_{c}[$ gon $]$ & $8 \mathrm{E}-07$ \\
\hline & $b\left[\frac{\text { mgon }}{\text { year }}\right]$ & 0.19 & $t[d a y]$ & 389.3 \\
\hline & $\sigma_{b}\left[\frac{\text { mgon }}{\text { year }}\right]$ & $6 \mathrm{E}-04$ & $\sigma_{t}[d a y]$ & 0.3 \\
\hline \multirow{4}{*}{94} & $b\left[\frac{g o n}{d a y}\right]$ & $7.41 \mathrm{E}-07$ & $c[$ gon $]$ & $4.5 \mathrm{E}-04$ \\
\hline & $\sigma_{b}\left[\frac{g o n}{d a y}\right]$ & 9E-09 & $\sigma_{c}[$ gon $]$ & $9 \mathrm{E}-07$ \\
\hline & $b\left[\frac{\text { mgoon }}{\text { year }}\right]$ & 0.27 & $t[d a y]$ & 383.0 \\
\hline & $\sigma_{b}\left[\frac{\text { mgon }}{\text { year }}\right]$ & $3 \mathrm{E}-03$ & $\sigma_{t}[$ day $]$ & 0.7 \\
\hline \multirow{4}{*}{95} & $b\left[\frac{g o n}{d a y}\right]$ & $-2.18 \mathrm{E}-07$ & $c[$ gon $]$ & $4.1 \mathrm{E}-04$ \\
\hline & $\sigma_{b}\left[\frac{g o n}{d a y}\right]$ & 4E-09 & $\sigma_{c}[$ gon $]$ & $9 \mathrm{E}-07$ \\
\hline & $b\left[\frac{\text { mgon }}{\text { year }}\right]$ & -0.08 & $t[$ day $]$ & 882.7 \\
\hline & $\sigma_{b}\left[\frac{m g o n}{\text { year }}\right]$ & $2 \mathrm{E}-03$ & $\sigma_{t}[d a y]$ & 1.5 \\
\hline
\end{tabular}

Table 9: Results of the tests of statistical hypotheses of linear trend of zenith angle.

\begin{tabular}{|c|c|c|c|c|c|}
\hline Zenith angle & $\mathbf{F}$ & $\mathbf{F}_{\alpha=\mathbf{0 . 5}}$ & $\mathbf{T}$ & $\mathbf{T}_{\alpha=\mathbf{0 . 2 5}}$ & $\mathbf{n}^{\prime}$ \\
\hline $\mathbf{9 1}$ & 354000 & 4 & 595 & 2 & 1579 \\
\hline $\mathbf{9 2}$ & 52549 & 4 & 229 & 2 & 1278 \\
\hline $\mathbf{9 3}$ & 109179 & 4 & 330 & 2 & 1606 \\
\hline $\mathbf{9 4}$ & 6556 & 4 & 81 & 2 & 386 \\
\hline $\mathbf{9 5}$ & 2474 & 4 & -50 & 2 & 1130 \\
\hline
\end{tabular}

and approximation curve of the zenith angle. Approximation curves were calculated again for the daily averages of temperature and the zenith angle. The figure of the comparison of the air temperature and the zenith angle to reference point the no. 93 can be seen in Fig. 12. It is obvious from this graph that the approximation curve of the zenith angle is shifted to the right compared the approximation curve of the temperature.

\section{Analysis of the variations of the measured values of the slope distance}

The initial assumption of the analysis was to perform this analysis as well as the analysis of the horizontal angle or zenith angle. It had to be replaced by the new approach. The measured data was divided into several time intervals as in the analysis of the horizontal direction, because a measured distance has significantly different size in each time interval. 


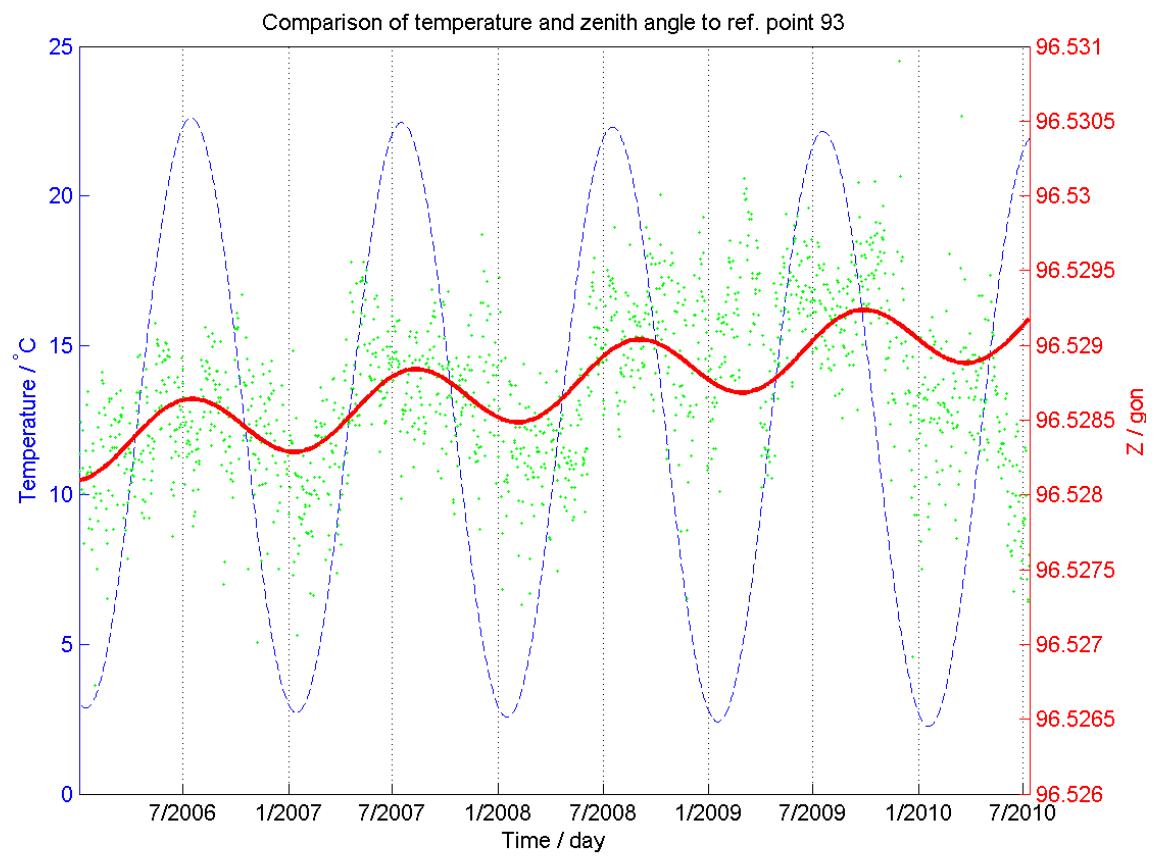

Figure 12: Comparison of approx. curves of zenith angle and temperature, ref. point no. 93.

The differences of slope distances between time intervals are almost $3 \mathrm{~cm}$. Measurements were divided into 7 time intervals (see Table 10), some of which are the same as in the case of the horizontal direction.

Table 10: Time intervals used in the analysis of slope distance.

\begin{tabular}{|c|c|c|c|}
\hline Interval number & Beginning of interval & End of interval & Number of days \\
\hline $\mathbf{1}$ & $1.1 .20060: 00$ & $26.9 .20060: 00$ & 268.0 \\
\hline $\mathbf{2}$ & $29.9 .20060: 00$ & $7.2 .200710: 00 \mathrm{am}$ & 131.4 \\
\hline $\mathbf{3}$ & $7.2 .200710: 00 \mathrm{am}$ & $30.11 .200710: 00 \mathrm{am}$ & 296.0 \\
\hline $\mathbf{4}$ & $28.1 .20080: 00$ & $23.10 .20080: 00$ & 269.0 \\
\hline $\mathbf{5}$ & $27.10 .20080: 00$ & $16.9 .200912: 00 \mathrm{am}$ & 324.5 \\
\hline $\mathbf{6}$ & $21.10 .200911: 00 \mathrm{am}$ & $11.3 .20109: 00 \mathrm{am}$ & 140.9 \\
\hline $\mathbf{7}$ & $11.3 .20109: 00 \mathrm{am}$ & $2.5 .20100: 00$ & 51.6 \\
\hline
\end{tabular}

The analysis of the slope distance was performed again by an approximation of the daily averages of the measured values by the $\mathrm{L}-\mathrm{H}$ function with one periodic member (1). There was a big problem to establish the approximate unknowns for calculating approximations in the seventh time interval, which is long just 51 days.

Calculated linear coefficients of L-H function were tested by the test of statistical hypotheses (3) in the same way as in the previous analyses.

Fig. 13 shows the daily averages of the slope distance for reference point no. 91 and their 


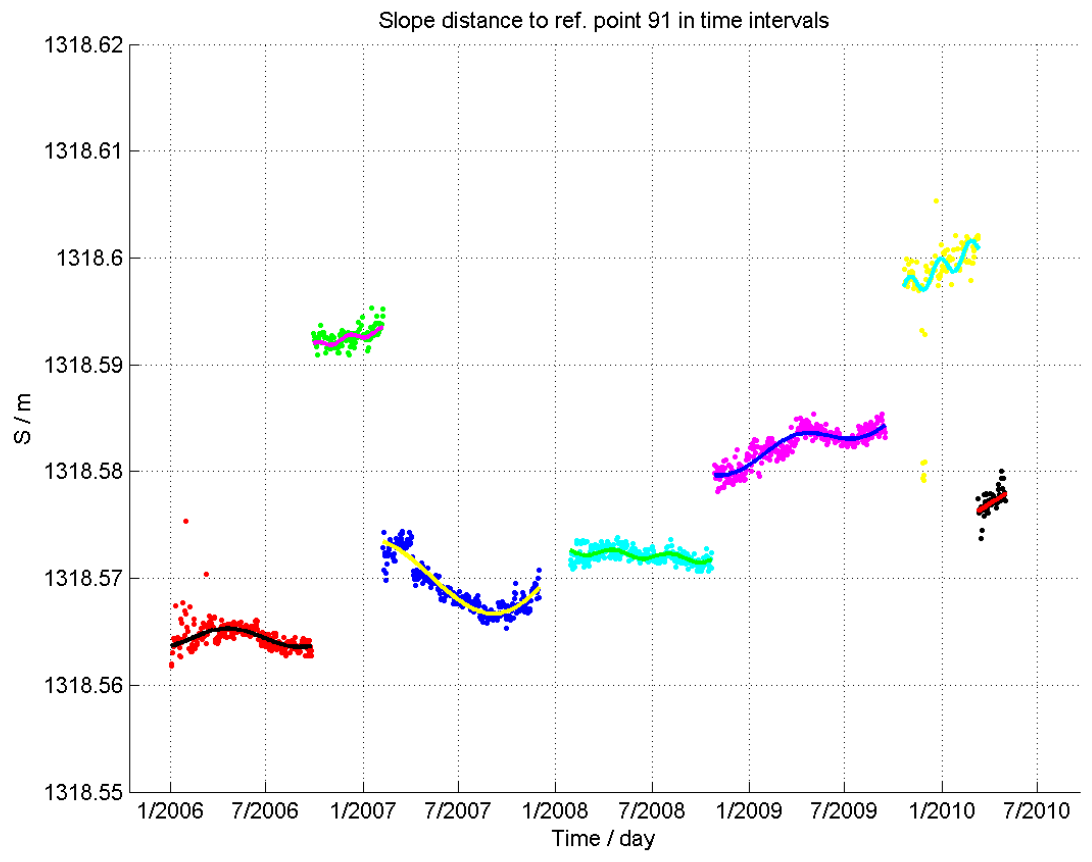

Figure 13: Approximation curve of slope distance, ref. point no. 91.

approximation curves. Values of some coefficients of the L-H function are listed in Table 11 for all reference points. The results of the tests of statistical hypotheses are listed in Table 12 .

The results of the analysis of the slope distance are not very clear. It is obvious from the figures that the reference point no. 92 shows the biggest variance and an indication of periodic changes. This reference point changes its position probably the most. The other points have different calculated values of amplitudes, periods and slopes of the regression lines in a comparison of time intervals as well as reference points. So, we can assume that the measured values of the slope distance are affected by measurement errors and changes in the position of reference points, which is the most evident for point 92 and the most stable is for points 93 and 95. We can also conclude from the similarity of the approximation of curves for difference points that the measurement errors and the movements of reference points are similar for all points. However, it is not easy to determine ratio of these two errors in the resulting error. Furthermore, it is necessary to consider, that this analysis is affected by the long-term movements of the objects, because the analysis uses the daily averages of the measured values. Therefore the daily movements of the target due to the sun exposure are not visible in the figures.

The values of the linear trend are different in size and direction. The calculated size of the linear trend is small and can be neglected despite the fact that the linear trend was confirmed tests of statistical hypotheses.

As well as the other analyzed variables, the approximation curves were compared with the 


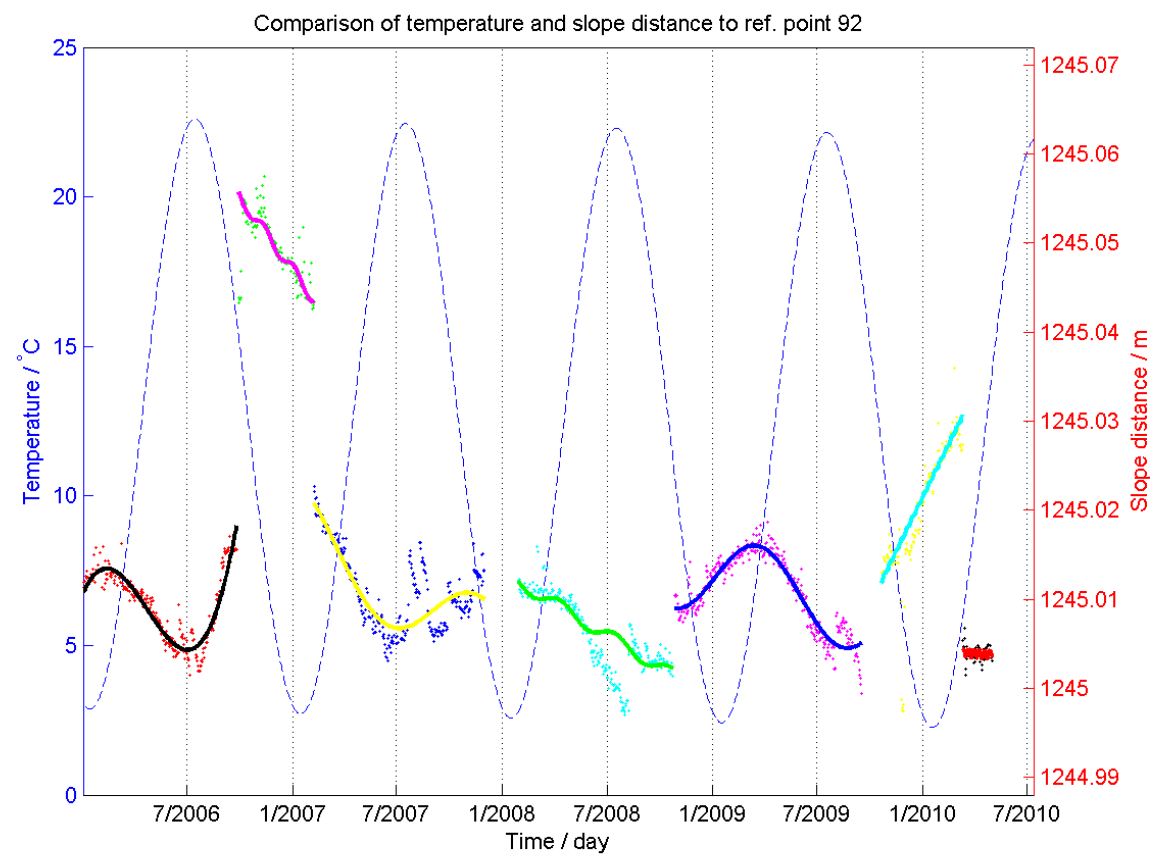

Figure 14: Comparison of approx. curves of slope distance and temperature, ref. point no. 92.

approximation curve of the temperature. The Fig. 14 shows the approximation curve for the reference point no. 92 .

There is not obvious the dependence values of the slope distance on the temperature. So we cannot declare that measured values of the slope distance significantly dependent on temperature.

\section{Conclusion}

This article describes the analysis of data measured by total station. The analysis should reveal a development of measured values during the long-term continuous monitoring. There were tested measured values of a horizontal direction, a zenith angle, a slope distance and calculated values of horizontal angles in the analysis. Input data were obtained from the monitoring system situated in the ČSA mine for the time period from January 2006 to July 2010.

The result of the analysis of the horizontal direction is the found linear trend of the measured data of size approximately $1 \mathrm{mgon} / \mathrm{month}$, which is probably caused by the first face only measurement. Furthermore, it was found that the measurements of the horizontal direction are influeced by many systematic and random errors, which disproportionately increases the variance of the measured values. A larger variance is especially noticeable in the winter and the summer, when the temperature gradient is the largest between the temperature inside and outside the shelter of the total station, which is caused by air condition and heating in 
Table 11: Significant coefficients of L-H function calculated in approximation of slope distance.

\begin{tabular}{|c|c|c|c|c|c|c|c|c|}
\hline \multirow{2}{*}{ Point } & \multirow{2}{*}{ coefficient } & \multicolumn{7}{|c|}{ Number of time interval (corresponds to Table 10) } \\
\hline & & 1 & 2 & 3 & 4 & 5 & 6 & 7 \\
\hline \multirow{4}{*}{91} & $b\left[\frac{m m}{m o n t h}\right]$ & 0.018 & 0.332 & 0.426 & -0.094 & 0.413 & 0.874 & 0.934 \\
\hline & $\sigma_{b}\left[\frac{\text { month }}{\text { month }}\right]$ & 0.0001 & 0.0001 & 0.002 & 0.0002 & 0.0001 & 0.0009 & 0.002 \\
\hline & $t[$ day $]$ & 276.14 & 63.02 & 556.92 & 107.26 & 248.13 & 57.40 & 2.96 \\
\hline & $\sigma_{t}[d a y]$ & 0.04 & 0.01 & 0.44 & 0.07 & 0.08 & 0.02 & 0.00 \\
\hline \multirow{4}{*}{92} & $b\left[\frac{m m}{\text { month }}\right]$ & 95.241 & -2.658 & -1.248 & -1.170 & -0.454 & 3.951 & -0.137 \\
\hline & $\sigma_{b}\left[\frac{\mathrm{mm}}{\text { month }}\right]$ & 0.007 & 0.0005 & 0.0008 & 0.0005 & 0.001 & 0.0007 & 0.017 \\
\hline & $t[d a y]$ & 1802.45 & 52.01 & 333.35 & 96.08 & 295.82 & 9.72 & 9.40 \\
\hline & $\sigma_{t}[$ day $]$ & 0.07 & 0.03 & 0.18 & 0.05 & 0.15 & 0.01 & 0.02 \\
\hline \multirow{4}{*}{93} & $b\left[\frac{m m}{\text { month }}\right]$ & -0.011 & -0.216 & -0.573 & 0.136 & 0.242 & 0.141 & 1.263 \\
\hline & $\sigma_{b}\left[\frac{m m}{\text { month }}\right]$ & 0.0001 & 0.0004 & 0.0002 & 0.0001 & 0.0007 & 0.0006 & 0.0001 \\
\hline & $t[d a y]$ & 288.33 & 19.94 & 278.90 & 251.38 & 161.82 & 23.65 & 23.57 \\
\hline & $\sigma_{t}[d a y]$ & 0.06 & 0.03 & 0.11 & 0.06 & 0.41 & 0.01 & 0.002 \\
\hline \multirow{4}{*}{94} & $b\left[\frac{m m}{\text { month }}\right]$ & -0.055 & -0.057 & -0.092 & & & & \\
\hline & $\sigma_{b}\left[\frac{\text { mm }}{\text { month }}\right]$ & 0.002 & 0.0002 & 1.2 & & & & \\
\hline & $t[d a y]$ & 193.72 & 36.36 & 36.58 & & & & \\
\hline & $\sigma_{t}[d a y]$ & 1.44 & 0.02 & 40.40 & & & & \\
\hline \multirow{4}{*}{95} & $b\left[\frac{m m}{m o n t h}\right]$ & & & -0.096 & -0.071 & -0.094 & 0.222 & 0.674 \\
\hline & $\sigma_{b}\left[\frac{m m}{\text { month }}\right]$ & & & 0.0002 & 0.005 & 0.0001 & 0.0001 & 0.0001 \\
\hline & $t[d a y]$ & & & 275.80 & 216.71 & 98.61 & 6.78 & 0.00 \\
\hline & $\sigma_{t}[$ day $]$ & & & 0.10 & 3.32 & 0.01 & 0.0002 & 0.01 \\
\hline
\end{tabular}

the shelter. Finally, there was made a comparison of the development of the measured values of the horizontal direction and temperature, but between these two variables was not proved any dependency.

A similar analysis for horizontal angles was carried out on the basis of the results of the analysis of the horizontal direction. This analysis was performed for the entire time period (the separation of measured values to the time intervals was not used). Most errors involved in the horizontal direction were deducted by the calculation. The analysis detected negligible linear trend and revealed annual period with amplitude 0.5 mgon. It was also carried out a comparison of the approximation curves of the horizontal angle and temperature, which had very similar progress. It can be concluded that the main cause of periodic changes in the values of the horizontal angle is just the air temperature.

Similar results were obtained in the analysis of the zenith angle. In this case, the linear trend was detected, too. The calculated linear trend is negligible in terms of the precision of the measurements. Annual periodic changes were detected in measured data, the amplitude of the periodic changes is up to 0.5 mgon. The periodic changes in the values of the zenith angle approximately correspond to changes of temperature during the year. So, the air temperature changes can be considered as the main cause of the periodic changes of the measured values of the zenith angle.

The results of the analysis of the slope distance were influenced by the need to divide the measured values to 7 time intervals, because between the time intervals are large differences 
Table 12: Results of the tests of statistical hypotheses of linear trend of slope distance.

\begin{tabular}{|c|c|c|c|c|c|c|c|c|}
\hline \multirow{2}{*}{ Point } & \multirow{2}{*}{ Variable } & \multicolumn{7}{|c|}{ Time interval } \\
\hline & & 1 & 2 & 3 & 4 & 5 & 6 & 7 \\
\hline \multirow{5}{*}{91} & $\mathbf{F}$ & $8.0 \mathrm{E}+03$ & $7.6 \mathrm{E}+06$ & $5.9 \mathrm{E}+04$ & $1.5 \mathrm{E}+05$ & $1.2 \mathrm{E}+07$ & $9.6 \mathrm{E}+05$ & $2.5 \mathrm{E}+05$ \\
\hline & $\mathbf{F}_{\alpha=0.5}$ & 4 & 4 & 4 & 4 & 4 & 4 & 4 \\
\hline & $\mathbf{T}$ & 261 & 2761 & 243 & -389 & 3485 & 980 & 495 \\
\hline & $\mathbf{T}_{\alpha=0.25}$ & 2 & 2 & 2 & 2 & 2 & 2 & 2 \\
\hline & $\mathbf{n}^{\prime}$ & 253 & 117 & 292 & 264 & 314 & 109 & 47 \\
\hline \multirow{5}{*}{92} & $\mathbf{F}$ & $1.8 \mathrm{E}+08$ & $3.2 \mathrm{E}+07$ & $2.6 \mathrm{E}+06$ & $4.8 \mathrm{E}+06$ & $2.1 \mathrm{E}+05$ & $3.1 \mathrm{E}+07$ & $6.3 \mathrm{E}+01$ \\
\hline & $\mathbf{F}_{\alpha=0.5}$ & 4 & 4 & 4 & 4 & 4 & 4 & 4 \\
\hline & $\mathbf{T}$ & 13388 & -5684 & -1606 & -2181 & -454 & 5564 & -8 \\
\hline & $\mathbf{T}_{\alpha=0.25}$ & 2 & 2 & 2 & 2 & 2 & 2 & 2 \\
\hline & $\mathbf{n}^{\prime}$ & 252 & 118 & 292 & 263 & 316 & 124 & 47 \\
\hline \multirow{5}{*}{93} & $\mathbf{F}$ & 13151 & 339437 & $9.7 \mathrm{E}+06$ & $4.7 \mathrm{E}+06$ & $1.1 \mathrm{E}+05$ & $4.9 \mathrm{E}+04$ & $8.6 \mathrm{E}+08$ \\
\hline & $\mathbf{F}_{\alpha=0.5}$ & 4 & 4 & 4 & 4 & 4 & 4 & 4 \\
\hline & $\mathbf{T}$ & -115 & -583 & -3121 & 2171 & 332 & 221 & 29319 \\
\hline & $\mathbf{T}_{\alpha=0.25}$ & 2 & 2 & 2 & 2 & 2 & 2 & 2 \\
\hline & $\mathbf{n}^{\prime}$ & 256 & 117 & 292 & 264 & 317 & 129 & 47 \\
\hline \multirow{5}{*}{94} & $\mathbf{F}$ & 973 & 121910 & 0 & & & & \\
\hline & $\mathbf{F}_{\alpha=0.5}$ & 4 & 4 & 5 & & & & \\
\hline & $\mathbf{T}$ & -31 & -349 & 0 & & & & \\
\hline & $\mathbf{T}_{\alpha=0.25}$ & 2 & 2 & 2 & & & & \\
\hline & $\mathbf{n}^{\prime}$ & 253 & 117 & 9 & & & & \\
\hline \multirow{5}{*}{95} & $\mathbf{F}$ & & & $3.7 \mathrm{E}+05$ & $3.2 \mathrm{E}+06$ & $2.2 \mathrm{E}+02$ & $4.8 \mathrm{E}+08$ & $4.6 \mathrm{E}+26$ \\
\hline & $\mathbf{F}_{\alpha=0.5}$ & & & 4 & 4 & 4 & 4 & 4 \\
\hline & $\mathbf{T}$ & & & -610 & -1783 & -15 & 21830 & $2.1 \mathrm{E}+13$ \\
\hline & $\mathbf{T}_{\alpha=0.25}$ & & & 2 & 2 & 2 & 2 & 2 \\
\hline & $\mathbf{n}^{\prime}$ & & & 206 & 318 & 264 & 128 & 36 \\
\hline
\end{tabular}

in measured values. Split into as many intervals decreased the possibility of finding periodic changes in the data. The linear trend was proofed in all time intervals, but the size and sign of the linear trend is different in the time intervals.

We can say that the data measured by the total station, are influenced by many effects. These effects can be probably significantly reduced by installing automatically opened windows in the shelter or uninstalling the heating and air conditioning from the shelter. Changes in the measured data with annual period are small and in terms of the accuracy of the measurements do not have greater importance.

\section{Acknowledgement}

Supported by grant SGS 2017 - Optimization of acquisition and processing of 3D data for purpose of engineering surveying, geodesy in underground spaces and laser scanning. 


\section{References}

[1] V. Ballu et al. "A seafloor experiment to monitor vertical deformation at the Lucky Strike volcano, Mid-Atlantic Ridge". In: JOURNAL OF GEODESY 83.2 (2009), pp. 147159. DOI: $10.1007 / \mathrm{s} 00190-008-0248-3$.

[2] T. Beran et al. "Measurement of Deformations by MEMS Arrays, Verified at Submillimetre Level Using Robotic Total Stations". In: Geoinformatics FCE CTU 12 (2014), pp. 30-40. DOI: 10.14311/gi.12.6.

[3] A. Berberan, M. Machado, and S. Batista. "Automatic multi total station monitoring of a tunnel". In: Survey Review 39.305 (2007), pp. 203-211. DOI: 10.1179/003962607X165177.

[4] C. Castagnetti et al. "Multi-sensors integrated system for landslide monitoring: critical issues in system setup and data management". In: European Journal of Remote Sensing 46 (2013), pp. 104-124. DOI: 10.5721/EuJRS20134607.

[5] Y. G. He and C. J. Zhao. Large-scale Bridge Distortion Measuring Technique Discussion. International Conference on Mechanics and Civil Engineering (ICMCE), Wuhan, Peoples Republic of China. Dec. 2014. DOI: 10.2991/icmce-14.2014.120.

[6] B. Klappstein, G. Bonci, and W. Maston. Implementation of real time geotechnical monitoring at an open pit mountain coal mine in western Canada. International multidisciplinary scientific symposium UNIVERSITARIA SIMPRO 2014, Petrosani, Romania. Oct. 2014.

[7] P. Stanislav and J. Blín. "Technical support of the service of automatic total station Leica TCR 2003A in operating conditions of the company Mostecká uhelná a.s." In: Acta Montanistica Slovaca 12.Special Issue 3/2007 (2007). ISSN 1335-1788, pp. 554558.

[8] M. Štroner et al. "Prague Castle Area Local Stability Determination Assessment By The Robust Transformation Method". In: Acta Geodynamica et Geomaterialia 11.4 (2014), pp. 325-336. DOI: 10.13168/AGG. 2014.0020.

[9] C. Tse and J. Luk. Design and implementation of automatic deformation monitoring system for the construction of railway tunnel: A case study in West Island Line. Joint International Symposium on Deformation Monitoring, Hong Kong, China. Feb. 2011.

[10] R. Urban. Surveying works during the deformation measurement of buildings. First printing. ISBN 978-80-01-05786-5. CTU Publishing House, Prague, 2015, p. 227.

Geoinformatics FCE CTU 15(1), 2016 
Geoinformatics FCE CTU 15(1), 2016 